\title{
Current Clinical Dental Practice Guidelines and the Financial Impact of COVID-19 on Dental Care Providers
}

\author{
Saqib Ali ${ }^{1, \odot ~ I m r a n ~ F a r o o q ~}{ }^{1, \odot}$ Maha Abdelsalam ${ }^{1}$ Jehan AlHumaid ${ }^{2}$
}

${ }^{1}$ Department of Biomedical Dental Sciences, College of Dentistry, Imam Abdulrahman Bin Faisal University, Dammam, Saudi Arabia 2Department of Preventive Dental Sciences, College of Dentistry, Imam Abdulrahman Bin Faisal University, Dammam, Saudi Arabia

\author{
Address for correspondence Imran Farooq, MSc, Department \\ of Biomedical Dental Sciences, College of Dentistry, Imam \\ Abdulrahman Bin Faisal University, Dammam 31441, Saudi Arabia \\ (e-mail: drimranfarooq@gmail.com).
}

\begin{abstract}
The novel coronavirus disease 2019 (COVID-19) has been acknowledged as a pandemic by the World Health Organization (WHO). The aim of this study was to review guidelines issued by different health regulatory bodies amid the COVID-19 outbreak and financial constraints faced by dentists globally. Relevant papers and news articles were identified in Google Scholar and PubMed. The search was made using the keywords "COVID-19," "COVID-19 and dentistry," and "the financial impact of COVID-19 on dentistry." Studies and news articles published in languages other than English were excluded and a final selection of 53 relevant studies, guideline documents, and news articles were made. The outbreak of COVID-19 has affected all businesses including general dental practices, which are suffering huge financial losses as they have been advised to provide only emergency dental care. These recommendations should be appreciated as a positive step but they have caused serious financial implications for dental practices. It can be concluded that current dental practice globally is lim-

Keywords

- COVID-19

- infection

- general dental practices

- dentistry ited to the provision of emergency treatments only. This step is appreciative, but has resulted in huge financial losses sustained by dental care providers (DCPs) worldwide. The governments and health regulatory bodies of developed countries are trying to help dental practices to evolve from this troublesome situation, but there is no visible policy from the underdeveloped world that could help the DCPs to save their practices from closing down due to the financial constraints.
\end{abstract}

\section{Introduction}

The novel coronavirus disease 2019 (COVID-19) came under the attention in December 2019. It has been declared as a pandemic after its global spread in multiple countries by the World Health Organization (WHO) on March 11, 2020. ${ }^{1}$ The COVID-19 fits in the family of single-stranded ribonucleic acid viruses called Coronaviridae. ${ }^{2}$ This family of viruses is believed to spread from animals to humans and evidence has shown that this novel coronavirus has a

DOI https://doi.org/ 10.1055/s-0040-1716307 ISSN $1305-7456$ resemblance to coronavirus species found in bats, making it zoonotic in nature. ${ }^{3}$ The severe acute respiratory syndrome coronavirus (SARS-CoV) and Middle East respiratory syndrome coronavirus (MERS-CoV) belong to the same family which were discovered in 2002 and 2012, respectively. ${ }^{4}$ The International Committee on Taxonomy of Viruses has given this novel coronavirus the name severe acute respiratory syndrome coronavirus 2 (SARS-CoV-2), ${ }^{5}$ although its other more popular given name is COVID-19 due to the similarity of its published genome sequence with that of 
$b$-coronaviruses like SARS-CoV and MERS-CoV. ${ }^{3}$ The CoVs can be considered as major pathogens of evolving respiratory disease outbreaks as they can cause human illnesses ranging from a common cold to severe respiratory diseases, as seen in patients affected by SARS-CoV and MERS. ${ }^{6}$ In humans, the SARS-CoV-2 can be found in salivary and nasopharyngeal secretions and can spread via direct contact or respiratory droplets. ${ }^{3}$ There are no vaccines available for COVID-19 and the only treatment available currently is the supportive treatment for symptoms and oxygen therapy. ${ }^{7}$ Reduction of transmission can be achieved by measures such as self-isolation and it can be correlated with isolation measures aggressively taken by China which have resulted in a progressive reduction of COVID-19 reported cases over the last few weeks. ${ }^{6}$

Dentistry is preferred by many students to be taken up as a professional career. ${ }^{8}$ However, due to the nature of dental procedures, aerosols (mist spray which is a mixture of water from instruments like dental drill and patients saliva) can be generated because of which dental professionals are at a higher risk of receiving the infection. ${ }^{9}$ Some common modes of possible transmission of infection of COVID-19 in a dental office are summarized in - Fig. 1. As the economic data evolve, the closure of various businesses, educational institutions, and multinational companies due to COVID-19 is expected to bring huge losses to world economies. ${ }^{10}$ Disorder of daily social life and routine travel for work, disruption of school and university education, deferrals of elective medical and dental procedures can have a very adverse impact on the developed world (countries with advanced service and industrial sector) whereas, the underdeveloped countries (those with less advanced service and industrial sector) are suffering more. ${ }^{10}$

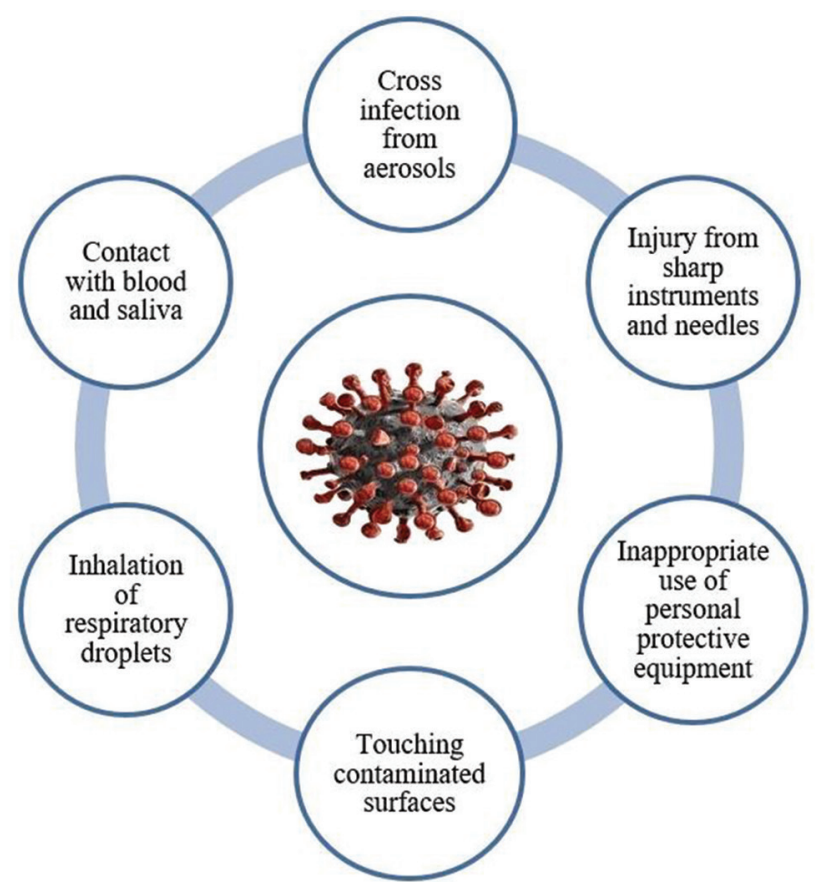

Fig. 1 Some common modes of possible transmission of COVID-19 in a dental practice. COVID-19, coronavirus disease 2019.

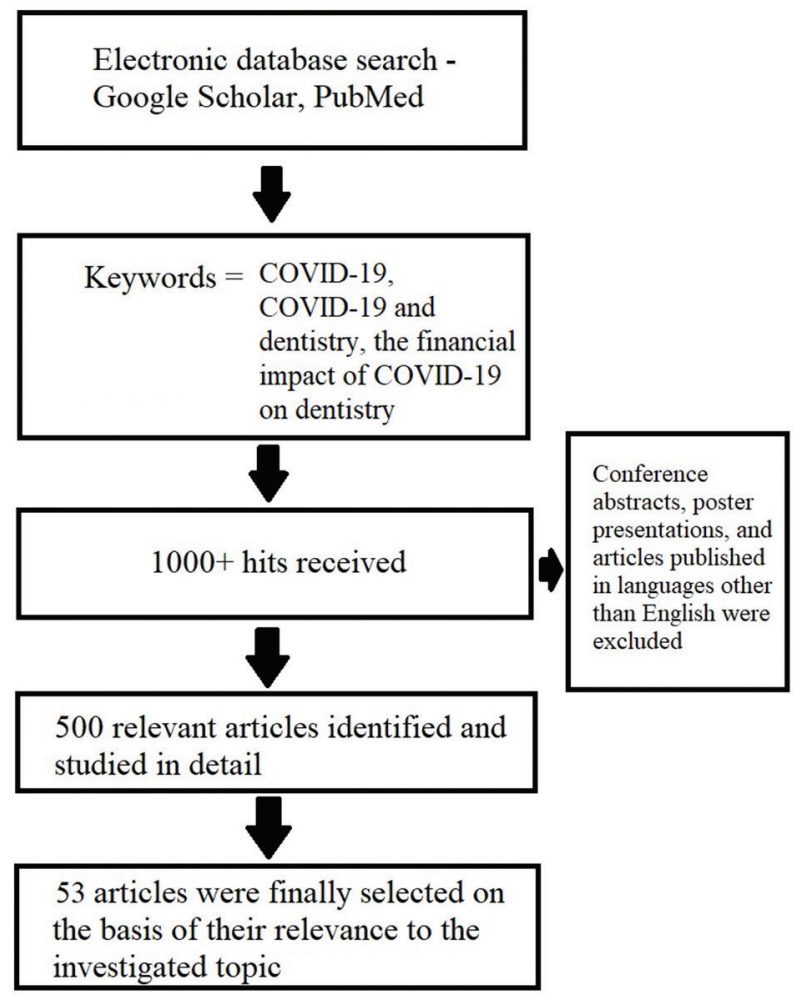

Fig. 2 Flowchart indicating search strategy involved in this study.

In this article, we have reviewed global guidelines provided by different countries that have been provided to their registered dental practitioners amid the COVID-19 outbreak. In addition, an overview of financial constraints faced by dentists globally and possible strategies to overcome these burdens acquired by some governments have also been reviewed. The search strategy involved in this article is summarized in $\boldsymbol{- F i g} . \mathbf{2}$.

\section{Global Guidelines amid COVID-19 Outbreak}

The outbreak of COVID-19 has forced health regulatory bodies all over the world to restrict dental care to only emergency procedures (urgent care needed to control pain, bleeding, or infection). Few examples are discussed below.

\section{National Health Commission of China Guidelines amid COVID-19 Outbreak}

The National Health Commission of China (NHCC) added COVID-19 to group B of infectious diseases along with other diseases like SARS and influenza in January, 2020. ${ }^{1}$ Post this step, dental treatment in many cities of China is restricted to emergency care only and that too with strict infection control measures and routine dental treatments are suspended till the situation of COVID-19 pandemic resolves. ${ }^{11,12}$

\section{American Dental Association Guidelines amid COVID-19 Outbreak}

The American Dental Association (ADA) has recommended on March 16, 2020 to all its registered dentists to postpone 
any elective treatment for the next 3 weeks. ${ }^{13}$ However, it is also recommended by ADA in the same press release to provide emergency dental care to the patients to reduce the burden on emergency departments in the hospital. ${ }^{13}$ Emergency dental treatment is usually defined as care provided to control bleeding, infection, and severe pain. ${ }^{14}$ Treatments such as routine oral examinations or radiographs, cleaning, preventive, and aesthetic procedures, restorations and removal of teeth without the pain, and regular orthodontics do not constitute an emergency. ${ }^{14}$ It should be mentioned here that all dental specialty organizations in the United States (U.S.) including American Association of Pediatric Dentistry, ${ }^{15}$ American Academy of Periodontology, ${ }^{16}$ American College of Prosthodontics, ${ }^{17}$ American Association of Orthodontists, ${ }^{18}$ American Association of Oral and Maxillofacial Surgeons, ${ }^{19}$ American Academy of Oral and Maxillofacial Radiology, ${ }^{20}$ American Association of Public Health Dentistry, ${ }^{21}$ American Academy of Oral and Maxillofacial Pathology, ${ }^{22}$ and American Association of Endodontists ${ }^{23}$ have also followed the guidelines of $\mathrm{ADA}^{14}$ and have recommended postponing all regular dental procedures.

\section{Consejo General (General Council), Spain Guidelines amid COVID-19 Outbreak}

The General Council of Spain has also advised limiting dental procedures to emergency care only in their press release dated March 19, 2020. ${ }^{24}$ According to General Council of Spain, emergency in dental care is limited to "acute infections, severe pain, major bleeding, and trauma to the facial area." 24 Prosthodontic treatments such as crown and bridges and damage of removable prosthesis and fractured or cavitated tooth without pain do not qualify as an emergency case. $^{24}$

\section{National Health Service, United Kingdom Guidelines amid COVID-19 Outbreak}

The guidelines of National Health Service, England published on March 5, 2020 state that in a primary dental care setting, regular treatments should be deferred and only emergency treatments should be provided to the patient. ${ }^{25}$ The office of the Chief Dental Officer (CDO) in Scotland has recommended stopping all aerosol-generating procedures (AGPs) in Scotland to curb the spread of COVID-19. ${ }^{26}$ The CDO of Wales has also suggested that routine dentistry is no longer practical, ${ }^{27}$ whereas, Health and Social Care Board of Northern Ireland has also recommended control of AGPs to control COVID-19 spread. ${ }^{28}$

\section{Guidelines from Patient Safety Center and the Ministry of Health (MOH) in Saudi Arabia amid COVID-19 Outbreak}

According to the "COVID-19 Safety Guide for Healthcare Workers" issued by the Saudi Patient Safety Center, all the health care facilities should scale up staffing capability by freeing up operation theaters and surgeries reserved for elective procedures so that these well-equipped facilities can be used to treat COVID-19 patients. ${ }^{29}$ According to this safety guide, emergency dental procedures such as facial infections, trauma, and bleeding are a priority and should be dealt with during the first 24 hours whereas, procedures such as extractions, implant placement, orthognathic surgery, and treatment for cleft lip and palate could be delayed for more than 30 days. ${ }^{29}$ The $\mathrm{MOH}$ in Saudi Arabia also recommended canceling all elective dental procedures and that emergencies should be handled while wearing recommended personal protective equipment and adhering strictly with the infection prevention protocols suggested by $\mathrm{MOH}^{30}$

\section{Guidelines from Other Parts of the World amid COVID-19 Outbreak}

In Canada, the Royal College of Dental Surgeons in Ontario has strongly recommended on March 15, 2020 to stop all nonessential dental procedures but continue with the emergency care. ${ }^{31}$ The same message was given by the Alberta Dental Association and College, Canada, ${ }^{32}$ and College of Dental Surgeons of British Columbia, Canada. ${ }^{33}$ The Indian Dental Association in a letter dated March 17, 2020 has strongly recommended all dental practitioners working in the country to stop nonurgent dental care till March 31, 2020.34 Asociación Odontológica Argentina has also recommended on its website to delay dental treatments until it's an emergency. ${ }^{35}$ The Philippine's Dental Association has also advised all the dentists to defer all nonessential procedures such as scaling, restoration of asymptomatic teeth, fluoride and aesthetic treatments, and orthodontic corrections. ${ }^{36}$ In New Zealand, the dental council has recommended providing only urgent and emergency care to the patients. ${ }^{37}$ In the Kingdom of Bahrain, National Health Regulatory Authority has issued guidelines on March 26, 2020 in which they have recommended to suspend all elective procedures and limit the provision of health services to emergency cases only. ${ }^{38}$ The Dubai Health Authority in their circular dated March 25, 2020 has also asked dental health centers and facilities to postpone all regular patients and receive only urgent cases. ${ }^{39}$

It is clear from the above-mentioned guidelines of various countries that at the present moment, dental care is restricted to only emergency treatments globally. All the patients who require nonurgent care are being asked to delay or cancel their appointments to avoid the spread of COVID-19. These steps taken are in line with the WHO recommendations so these actions taken by dental regulatory bodies worldwide should be appreciated as a positive step but on the other hand, it has serious financial implications for dental care providers (DCPs). These financial difficulties faced by DCPs all over the world are now discussed below.

\section{Financial Constraints Faced by DCPs Globally}

The New York Times in their recent article published on March 15, 2020 have identified dentists as workers who face the highest risk of becoming sick with COVID-19.40 Due to this, complete closure of dental practices or restricting working hours and performing only emergency dental procedures is becoming the common norm during COVID-19 pandemic.

The Irish Dental Association (IDA) has conducted a survey of 369 DCPs to evaluate the impact of COVID-19 outbreak on 
their practices. ${ }^{41}$ The results demonstrate that around $20 \%$ of DCPs have closed their practices (for a limited time or permanently), 76\% are expecting a plunge in their practice income by over $70 \%$, and $60 \%$ do not expect to receive financial commercial insurance. ${ }^{42}$ This survey demonstrates the serious financial pressure on the dental profession that is being faced by Irish DCPs. The British Dental Association has also directed the same and mentioned that dental practices could suffer crippling losses due to the COVID-19 pandemic. ${ }^{42}$ In the United States, some of the dentists have already closed their dental practices, whereas some are not closing it due to the fear of income loss and salaries not being delivered to their employees. ${ }^{43} \mathrm{~A}$ recent data from the United States indicated that 79\% DCPs reported that their practices are closed for routine procedures. ${ }^{44}$ Another new data which contains over 4,000 responses from the participants, suggests that as of May 15, 2020, $42 \%$ dentists have reported that their income has stopped completely as compared with $4 \%$ lawyers, $2 \%$ pharmacists, and $1 \%$ physicians. ${ }^{45}$ This clearly shows that the dentistry is the worst hit profession by the COVID-19 pandemic. A recent study from Germany has indicated that the longer the COVID-19 crisis continues, the greater will be the monetary distress on dental practices. ${ }^{46}$ Data from other countries are not available as yet but it is highly anticipated that in the coming months, these reports will emerge and will show huge losses suffered by DCPs and dental practices during this period of COVID-19 outbreak.

\section{Strategies to Overcome Financial Losses Incurred by Dental Practices}

To address the issue of financial losses, the governments should assist dental regulatory bodies or DCPs in providing financial help or loans so that the dental profession could move away from the brink of collapse. Many developed countries are doing this and other countries should follow their example as well.

The Government of Canada came up with COVID-19 Economic Response Plan on March 18, 2020 to provide sustenance to businesses and reserved $\$ 27$ billion to support businesses. ${ }^{47}$ The DCPs in Canada can apply for this and support their practices in this difficult time. In the United Kingdom (UK), many dental practices are looking up to their insurance companies to seek help for their losses. ${ }^{48}$ Most of the insurance policies in the United Kingdom have a "business interruption" clause which could be due to forced closure of practices due to infectious diseases. ${ }^{48}$ The UK government is also calling business owners to communicate with them for loans or credit if they need assistance to pay for salaries, supplies, or consumables. ${ }^{4}$ The ADA has also advised DCPs to consult their insurance policymakers and explore the area of business interruption occurred due to diseases such as COVID-19.49 The ADA has also recommended the DCPs to seek help from U.S. Small Business Administration's Economic Injury Disaster Loan program under which small businesses like dental practices may apply loans. ${ }^{49}$ In the UK, NHS-based dental practices also receive some relief due to COVID-19 caused losses. ${ }^{42}$ In Ireland, the IDA has stated on its official website that the government is ready to support businesses (including dental practices) affected by COVID-19 pandemic and is prepared to provide COVID-19 business loan ranging between $€ 5 \mathrm{~K}$ and€50K. ${ }^{50,51}$ The Saudi government has taken significant measures to inhibit the damage to the private sector amid the COVID-19 outbreak. Business owners can request up to 3 months of compensation amounting to $60 \%$ of the employee's salary. ${ }^{52}$ The Saudi government has also ensured a stimulation of the economy in which 70bn riyals are reserved for exemption of taxes and 50bn riyals will be allocated for banks and other financial institutions so that they can support private enterprises, including dental practices. $^{52}$

While this is the situation of developed countries, no policy has been put forward by the governments of underdeveloped countries regarding the recovery of financial losses gained by dental practices due to the COVID-19 pandemic.53 It is recommended that the developed countries should continue the support of DCPs through financial means whereas, the underdeveloped countries should come forward with a policy to help their registered DCPs morally and financially in this critical time.

\section{Conclusion}

It can be concluded that current dental practice globally is limited only to the provision of emergency treatments. This step is appreciative as it curtails the spread of COVID-19 but has resulted in huge financial losses sustained by dental practices worldwide. The governments and health regulatory bodies of developed countries are trying to help practices to evolve from this difficult situation but on the other hand, there is no visible policy from the underdeveloped world that could help DCPs to save their practices from closing due to monetary constraints. Although work is on-going towards the development of COVID-19 vaccination, in its absence and definitive treatment, it is also emphasized that post-COVID-19 global recovery, all governments, and health regulatory bodies should come up with new infection control protocols for dental clinics to ensure health and safety of patients and dental practice staff. In addition, all governments should support the profession of dentistry by helping the DCPs morally and monetarily.

\section{Conflict of Interest}

None declared.

\section{References}

1 Ali S, Noreen S, Farooq I, Bugshan A, Vohra F. Risk assessment of healthcare workers at the frontline against COVID-19. Pak J Med Sci 2020;36(COVID19-S4):S99-S103

2 Hamid H, Khurshid Z, Adanir N, Zafar MS, Zohaib S. COVID19 pandemic and role of human saliva as a testing biofluid in point-of-care technology 2020. Eur J Dent 2020;14(suppl S1):S123-S129 doi:10.1055/s-0040-1713020.

3 Ather A, Patel B, Ruparel NB, Diogenes A, Hargreaves KM. Coronavirus disease 19 (COVID-19): implications for clinical dental care. J Endod 2020;46(5):584-595 
4 Wax RS, Christian MD. Practical recommendations for critical care and anesthesiology teams caring for novel coronavirus (2019-nCoV) patients. Can J Anaesth 2020;67(5): 568-576

$5 \mathrm{Wu}$ Y, Ho W, Huang Y, et al. SARS-CoV-2 is an appropriate name for the new coronavirus. Lancet 2020;395(10228):949950 doi:10.1016/S0140-6736(20)30557-2

6 Paules CI, Marston HD, Fauci AS. Coronavirus infections-more than just the common cold. JAMA 2020;323(8):707-708

7 Casadevall A, Pirofski LA. The convalescent sera option for containing COVID-19. J Clin Invest 2020;130(4):1545-1548

8 Al-Hallak KR, Nassani MZ, Heskul MM, Doumani MD, Darwish M. Reasons for choosing dentistry as a career among dental students in Saudi Arabia. Eur J Dent 2018;12(2):275-280

9 Ahmed MA, Jouhar R, Ahmed N, et al. Fear and practice modifications among dentists to combat novel coronavirus disease (COVID-19) outbreak. Int J Environ Res Public Health 2020;17(8):2821

10 Ioannidis JPA. Coronavirus disease 2019: the harms of exaggerated information and non-evidence-based measures. Eur J Clin Invest 2020;50(4):e13222

11 Li ZY, Meng LY. The prevention and control of a new coronavirus infection in department of stomatology [in Chinese]. Zhonghua Kou Qiang Yi Xue Za Zhi 2020;55(0):E001

12 Meng L, Hua F, Bian Z. Coronavirus disease 2019 (COVID-19): emerging and future challenges for dental and oral medicine. J Dent Res 2020;99(5):481-487

13 American Dental Association. Available at: https://www.ada. org/en/press-room/news-releases/2020-archives/march/ ada-calls-upon-dentists-to-postpone-elective-procedures. Accessed May 20, 2020

14 ADA.org. What constitutes a dental emergency? Available at: https://success.ada.org/ /media/CPS/Files/Open\%20Files/ ADA_COVID19_Dental_Emergency_DDS.pdf. Accessed June 4, 2020

15 American Academy of Pediatric Dentistry. Available at: https:// www.aapd.org/about/about-aapd/news-room/covid-19/. Accessed June 4, 2020

16 American Academy of Peridontology. Available at: https:// www.perio.org/members/COVID-19. Accessed June 4, 2020

17 American College of Prosthodontists. Available at: https:// www.prosthodontics.org/covid-19/. Accessed June 4, 2020

18 American Association of Orthodontists. COVID resources for Orthodontists. Available at: https://www1.aaoinfo.org/ covid-19/. Accessed June 4, 2020

19 AAOMS. COVID-19 updates. Available at: https://www.aaoms. org/news/covid-19-updates. Accessed June 4, 2020

20 American Academy of Oral and Maxillofacial Radiology. Available at: https://www.aaomr.org/. Accessed June 4, 2020

21 American Association of Public Health Dentistry. Available at: https://aaphd.memberclicks.net/covid-19-resources. Accessed June 4, 2020

22 The American Academy of Oral and Maxillofacial Pathology. Available at: http://www.aaomp.org/. Accessed June 4, 2020

23 American Association of Endodontists. Available at: https:// www.aae.org/specialty/clinical-resources/covid-19-updatesresources/. Accessed June 4, 2020

24 General Council of Dentists, Spain. Available at: https://www. consejodentistas.es/comunicacion/actualidad-consejo/notasde-prensa-consejo/item/1739-recomendaciones-de-buenas-practicas-para-la-atencion-de-urgencias.html. Accessed June 4, 2020

25 National Health Services, UK. Available at: https://www.england. nhs.uk/coronavirus/primary-care/dental-practice Accessed June 4,2020 .
26 NHS Dental Services. Available at: https://www.gdc-uk.org/ docs/default-source/covid-19/ocdo-scotland-letter.pdf?sfvrsn=bf8fdcef_2. Accessed June 4, 2020

27 General Dental Council, UK. Available at: https://www.gdc-uk. org/docs/default-source/covid-19/amber-alert-wales.pdf?sfvrsn=ad3d71b1_2. Accessed June 4, 2020

28 Business Service Organization. Available at: http://www.hscbusiness.hscni.net/pdf/COVID\%2019\%20Further\%20Advice\%20 for\%20DCPs.pdf. Accessed June 5, 2020

29 Saudi Patient Safety Center. Available at: https://spsc.gov.sa/ English/PublishingImages/Pages/guidelines/guideline7apr. pdf. Accessed June 5, 2020

30 Ministry of Health, Saudi Arabia. Available at: https://www. moh.gov.sa/Pages/Default.aspx. Accessed June 5, 2020

31 Royal College of Dental Surgeons of Ontario. Available at: https://www.rcdso.org/en-ca/rcdso-members/dispatch-magazine/articles/5286. Accessed June 5, 2020

32 Alberta Dental Association and College, Canada. Available at: https://www.dentalhealthalberta.ca/information-aboutnovel-coronavirus-covid-19-for-dental-patients-and-practitioners/. Accessed June 5, 2020

33 College of Dental Surgeons of British Columbia. Available at: https://www.cdsbc.org/Pages/covid-19-faq.aspx. Accessed June 6,2020

34 Indian Dental Association. Available at: https://www.ida.org. in/pdf/20200317_Advisory_on_Corona.pdf. Accessed June 6, 2020

35 Asociación Odontológica Argentina. Available at: https://www. aoa.org.ar/coronavirus-nuevas-recomendaciones-de-la-omspara-profesionales-de-la-salud/. Accessed June 6, 2020

36 ABS-CBN Corporation. Available at: https://news.abs-cbn.com/ news/03/18/20/dentists-issue-guidelines-to-avoid-covid-19spread. Accessed June 6, 2020

37 Ministry of Health. Available at: https://dcnz.org.nz/assets/ Uploads/COVID/Guidelines-at-Alert-Level-4-updated31Mar20.pdf. Accessed June 6, 2020

38 NHRA Bahrain. Available at: https://www.nhra.bh/Media/ Announcement/MediaHandler/GenericHandler/documents/Announcements/Announcement2020_Circular\%20 No.\%20(15)\%202020_To\%20All\%20Private\%20Healthcare\%20 Facilities_Temporary\%20Suspension\%20of\%20Services\%20 and $\% 20$ Unnecessary $\% 20$ Medical $\% 20$ Procedures $\% 20$ (Arabic)_20200326.pdf. Accessed June 6, 2020

39 Dubai Health Authority. Available at: https://services.dha. gov.ae/sheryan/wps/portal/home/circular-details?circularRefNo=CIR-2020-00000108\&isPublicCircular=1\&fromHome=true. Accessed June 6, 2020

40 The New York Times. Available at: https://www.nytimes.com/ interactive/2020/03/15/business/economy/coronavirus-worker-risk.html. Accessed June 7, 2020

41 IDA Irish Dental Association. Available at: http://irishdentalassociation.newsweaver.com/newsletter/13ctcsav7cz1cys22x$\mathrm{tzj} 2$ ?a=1\&p=56657247\&t=22322575. Accessed June 7, 2020

42 British Dental Association. Available at: https://bda.org/advice/ Coronavirus/Pages/latest-updates.aspx. Accessed June 7, 2020

43 The Salt Lake Tribune. Available at: https://www.sltrib.com/ news/2020/03/17/some-utah-dentists-are/. Accessed June 7 , 2020

44 Dental Tribune. Available at: https://us.dental-tribune.com/ news/dentists-report-financial-impact-of-covid-19-on-theirpractices/. Accessed July 7, 2020

45 Student Loan Planner. Available at: https://www.studentloanplanner.com/dentists-financial-crisis-coronavirus/. Accessed July 7, 2020

46 Schwendicke F, Krois J, Gomez J. Impact of SARS-CoV2 (Covid-19) on dental practices: Economic analysis. J Dent 2020;99:103387 
47 Government of Canada. Available at: https://www.canada.ca/ en/department-finance/news/2020/03/canadascovid-19-economic-response-plan-support-for-canadians-andbusinesses.html. Accessed July 7, 2020

48 Dentistry magazine. Available at: https://www.dentistry. co.uk/2020/03/19/coronavirus-financial-impact-dentistry/. Accessed July 7, 2020

49 ADA Center for Professional Success. Available at: https:// success.ada.org/en/practice-management/patients/coronavirus-frequently-asked-questions. Accessed July 7, 2020

50 Irish Dental Association. Available at: http://irishdentalassociation.newsweaver.com/newsletter/40uglfzc4qy1cys22xtz$\mathrm{j} 2$ ? $\mathrm{a}=1 \& \mathrm{p}=56657247 \& \mathrm{t}=22322575$. Accessed July 7, 2020
51 Microfinance Irelnad. Available at: https://microfinanceireland.ie/loan-packages/covid19/. Accessed July 7, 2020

52 Arabian Business. Available at: https://www.arabianbusiness. com/banking-finance/444303-saudi-government-to-cover60 -of-private-sector-salaries-hit-by-covid-19. Accessed July 7 , 2020

53 Farooq I, Ali S. COVID-19 outbreak and its monetary implications for dental practices, hospitals and healthcare workers. Postgrad Med J 2020;96(1142):791-792 